\title{
Research on the Teaching Reform of Higher Vocational Courses of Logistics System Planning and Design Based on P-PBL
}

\author{
Bo Wei \\ Hunan Modern Logistics College \\ Changsha, China
}

\begin{abstract}
The course "Logistics System Planning and Design" has an extremely important position in the logistics engineering technology major of higher vocational education. This article analyzes the problems existing in the teaching of this course, and combines the two modes of "problem-based learning" and "project-based learning" to construct a P-PBL course teaching mode composed of teaching philosophy, teaching content, teaching process, teaching assessment, and other parts.
\end{abstract}

Keywords-teaching reform; problem-based learning; project-based learning; $P$-PBL

\section{INTRODUCTION}

The "Problem Based Learning" (PBL) teaching mode is based on problems. Teachers set up complex and meaningful problem situations to guide students to link learning to problems, to solve real-life problems through group collaboration and autonomous inquiry, and to learn the scientific knowledge behind the problems to form problemsolving skills and ability to learn autonomously. Its core idea is to stimulate students' subjective consciousness and creative thinking, enable students to learn learning methods, to meet the needs of lifelong education, and to improve the overall quality of students.

PBL mode was founded in 1969 by Barrows, a professor of neurology in the United States, based on psychology at Mcmaster University in Canada. It was then extended to the United States and Australia, and was widely used in some universities' medical courses and developed rapidly. It has gradually been perfected to form a complete, scientific, and mature teaching mode, and has gradually expanded to other professional education fields such as law, engineering, education, social studies, and has become one of the more popular and advanced teaching methods in the world.

Project Based Learning, which is also known as "projectoriented" teaching, organizes students to truly participate in the design, implementation, summary, and evaluation of projects, and completes teaching tasks during project implementation. In project-oriented curriculum teaching, project activities are the subject of students and teachers, and are realistic project activities constructed by teachers based on the relevance of multiple knowledge. Its ultimate purpose is to cultivate compound talents who are consciously learning, have good self-directed ability and innovative consciousness, and are responsible for their own lives.

\section{COURSE Characteristics AND MAIN PROBLEMS IN TEACHING}

\section{A. Course Characteristics}

"Logistics System Planning and Design" is a core professional course of logistics engineering technology major in higher vocational education, which has strong theoretical, practicalness and comprehensiveness. This course not only includes the basic courses of logistics majors such as Fundmentals of Logistics Engineering, Warehousing and Distribution Practice, Logistics Technology and Logistics Equipment, etc., but also integrates Systems Engineering, Operations Research, Management and other related content. This has played a vital role in cultivating students' ability in logistics planning, design, and optimization, but it is also the most difficult course to teach and study in the entire professional curriculum system.

The logistics system planning and design course is also a course that has important guiding significance in the method and practice of the graduation design of the logistics engineering technology major. Through the study of this course, students have a comprehensive and in-depth understanding of the planning and design of logistics systems, and can use the principles, methods, and techniques of logistics system planning and design to rationally plan and design the logistics system of enterprises. Through the study of this course, students understand and master the main content of logistics system planning and design, and have a comprehensive recognition and understanding of the basic principles and basic knowledge of logistics system planning and design. Mastering its application in logistics practice is the basic ability of students to solve practical problems in the field of logistics system planning and design, which lays a good foundation for students to quickly adapt to logistics work and carry out related logistics work. 
problem-learning inquiry as the goal to improve students' problem-solving skills and autonomous learning ability.

1) Contradiction between learning foundation and course difficulty: The core curriculum in the professional curriculum system integrates Systems Engineering, Operations Research, Management, and other content. It has the characteristics of many concepts, strong theories, many formulas, and strong practicality and practicality. The course content includes both abstract macro-planning theories and technical methods that are difficult to understand. Students must not only learn the basic technical methods of logistics planning and design, but also be able to design, optimize, and evaluate actual cases, and propose a reasonable implementation plan. Higher vocational students have a large gap with their theoretical foundation and learning ability, and their logical thinking and comprehensive application ability are poor. Therefore, it is difficult for them to understand and master the theoretical methods during the learning process, let alone to be flexible.

2) Contradiction between learning interest and teaching method: Traditional classroom teaching is dominated by teacher lectures. Most of the time in the classroom is taught by the teacher, and then a small amount of time is left for students to digest and connect. During this whole process, students' learning is passive. In addition, theoretical knowledge points are inherently difficult to understand. In particular, some principles, models, and formulas are insurmountable to the existing ability foundation of vocational students. Over time, the more students do not understand, the more they are unwilling to learn. Their enthusiasm for learning gradually decreases with the depth of the course.

3) Contradiction between the abstractness of learning and the intuitiveness of application: The goal of the course teaching is to learn through theoretical and technical methods, so that students can propose corresponding reasonable solutions to different practical problems. In the actual teaching process, even if students barely understand the knowledge points, it is difficult to use them flexibly in actual cases. The key reason is that the theoretical methods of learning are relatively abstract, while the actual cases are more specific, but because the students have no work experience, their understanding of the cases is relatively abstract and vague, it is impossible to produce intuitive cognitive expressions only through the expression of words and pictures. This therefore leads to a disconnection between theoretical learning and practical application.

\section{P-PBL-BASEd COURSE TEACHING MODE OF LOGISTICS SYSTEM PLANNING AND DESIGN}

In order to solve the problems in the teaching process of "Logistics System Planning and Design" in higher vocational education, a comprehensive teaching mode based on P-PBL was designed in the teaching reform, that is, combining the "problem-based learning" mode with the "project-based learning" mode, using project teaching as a carrier and

\section{A. Emphasizing Student-centeredness in Teaching Philosophy}

The design of the teaching model of "Logistics System Planning and Design" based on P-PBL has changed the previous teaching concept of "Teaching-oriented and Teacher-centered", instead emphasizing the teaching concept of "Learning-oriented and Student-centered". And around how to enable students to actively participate in the learning process of knowledge, so that they comprehensively and systematically master the theory and methods of logistics planning and design, the curriculum teaching system is designed.

\section{B. Analyzing and Discussing Teaching Content Around Project Tasks}

In the teaching content of "Logistics System Planning and Design" based on P-PBL, through the targeted introduction of more realistic logistics enterprise operation projects, the "logistics design competition" that college students participate in all year round and other projects, students are required to use the planning and design methods and evaluation methods they have learned to conduct indepth analysis and design evaluation of these items. In this way, students review the project with problems, and apply the knowledge and methods of planning and design to analyze and study the problems of "Logistics System Planning and Design" that may exist in reality. This not only strengthens the results-oriented learning, cultivates students' scientific research thinking, enhances students' inquiry learning ability, but also forms students' autonomous learning.

\section{Strengthening Interaction in the Teaching Process and Implementing "Flipped Classroom"}

In the implementation of classroom teaching, open and inquiry learning is adopted, and students are supplemented with personalized guidance. Several learning groups are established to stimulate students' awareness of teamwork and discussion enthusiasm.

First, the teacher arranges the discussion tasks according to the problem assignments and problems encountered or raised by each group of students during the pre-class study. Students can make full use of this time to discuss and exchange ideas with their learning partners, form group conclusions, and present reports. Teachers understand the students' understanding and mastery of knowledge points and skill requirements through the feedback of each group, and explain and summarize the knowledge points in a targeted manner. If conditions permit, you can use information technology to strengthen the understanding of learning content. Taking the storage center optimization design project of the distribution center as an example, teachers and students can connect with relevant personnel of the enterprise through mobile phone video communication, visually present the specific situation of the design object, 
flexible, and personalized evaluation mechanism with students as the mainstay, process evaluation as the mainstay, and stage evaluation and end evaluation as the supplement. If conditions permit, enterprises can be invited to participate in the evaluation, and student representatives can also be selected to participate. In this way, students can evaluate each other from the perspective of students, and improve their enthusiasm for participation, so as to achieve objective, fair and comprehensive evaluation.

\section{CONCLUSION}

The course of "Logistics System Planning and Design" is highly theoretical, practical and comprehensive. Its course content is directly linked to the professional graduation design. It has a strong practical guidance role for practical work, so it has an extremely important position in the core courses of logistics engineering technology major in higher vocational education. However, facing the teaching contradiction of higher vocational students with poor learning foundation and poor abstract thinking, and low learning motivation, the traditional teaching model has been difficult to adapt. This paper proposes to combine the two teaching modes of "question-based learning" and "projectbased learning", with project teaching as the carrier and problem-learning inquiry as the goal. The purpose of this is to cultivate and improve students' problem-solving skills and self-learning abilities.

\section{REFERENCES}

[1] Sun Yubo. Discussion on the reform of the course of Logistics System Planning and Design Based on Application [J]. Logistics Scitech, 2014, 07. (in Chinese)

[2] Zhang Dezhi, Li Shuangyan. Application of case law in teaching of logistics system planning and design [J]. Education Forum, 2016, 01. (in Chinese)

[3] Geng Huijun. Research on the application of the flipped classroom teaching model: Taking the course of "Logistics System Planning and Design" as an example [J]. Logistics Sci-tech, 2017, 07. (in Chinese)

[4] He Binghua, Hu Huifang. Instructional design of personalized learning in flip classroom-Taking the course of "Logistics System Planning and Design" as an example [J]. Journal of Zhejiang Wanli University, 2017, 07. (in Chinese) combination of theoretical teaching and experimental teaching allows students to master the ability of arithmetic operations while receiving theoretical knowledge, give full play to students 'subjective initiative, mobilize students' enthusiasm for learning and innovative thinking, and enable students to integrate and learn from course knowledge.

\section{E. Trying to be Objective, Fair, and Comprehensive in the Evaluation}

Curriculum assessment is both a test of student learning and a measure of teacher's teaching effectiveness. It is not only necessary to assess students' mastery of basic theory and basic knowledge, but also to judge whether students have the ability to use basic principles to analyze and solve practical problems. In the assessment process of the "Logistics System Planning and Design" course, the students' theoretical literacy, practical skills, and innovation ability should be considered. Schools should establish an open, 